SHORT REPORT

\title{
Cashew nut allergy is associated with a high risk of anaphylaxis
}

\section{Davoren, J Peake}

Arch Dis Child 2005;90:1084-1085. doi: 10.1136/adc.2005.073817

Cashew allergy is an evolving clinical problem. A retrospective chart review of 213 children with peanut or tree nut allergy was undertaken over a 42 month period. Anaphylaxis to cashew nut was more common than to peanut $(74.1 \%$ v $30.5 \%)$. Children with cashew allergy are at risk of anaphylaxis.

M uch has been published in the literature about the increasing incidence of peanut allergy. Some children who are peanut allergic are also allergic to tree nuts, ${ }^{1-3}$ and some are allergic to tree nuts without associated peanut allergy. ${ }^{23}$ There also appears to be an increase in the prevalence of cashew allergy in children. ${ }^{45}$ Data from our department suggests that over the last few years, an increasing number of children with cashew allergy have presented and that the risk of anaphylaxis in these children is at least equivalent to that of peanut. A retrospective review of children with peanut, cashew, or other tree nut allergy seen by a single tertiary paediatric allergist was undertaken, with a view to evaluating these observations.

\section{METHODS}

A retrospective chart review was undertaken of all children less than 17 years of age who presented with nut allergy seen over a 42 month period. A single paediatric allergist in Brisbane, Australia saw all patients. Patients who presented for investigation of nut allergy due to a family history alone or for investigation of causes of eczema and who were incidentally found to be positive for nuts on skin prick testing were excluded.

Clinical symptoms were divided into anaphylaxis and nonanaphylaxis. Anaphylaxis was defined as a rapidly evolving generalised multisystem allergic reaction characterised by one or more symptoms or signs of respiratory and/or cardiovascular involvement and involvement of other systems (skin and/or gastrointestinal tract). ${ }^{6}$ Non-anaphylaxis symptoms were defined as cutaneous and/or gastrointestinal symptoms and signs without respiratory or cardiovascular involvement. In cases where patients had experienced multiple reactions prior to being seen, the worst clinical reaction was recorded. Reactions were considered to be convincing if ingestion of or contact with the suspected nut resulted in a reaction within 60 minutes of exposure.

Statistical analysis was undertaken using the STATA version 8.0 statistics package for Windows (StataCorp, USA). Fisher's exact test was used.

Ethics committee approval was obtained to undertake the study.

\section{RESULTS}

Over 42 months, 213 patients (118 males and 95 females) were seen with peanut and/or tree nut allergy. Of these, 177 patients $(83.1 \%)$ had peanut allergy, 27 (12.6\%) had cashew allergy, and 9 (4.2\%; 2 each to almond and pecan, 1 each to hazelnut and walnut, and 3 were a mixture of nuts) had allergy to other tree nuts. In patients with peanut allergy, $30.5 \%$ had anaphylaxis while in the patients with cashew allergy, $74.1 \%$ had anaphylaxis $(\mathrm{p}<0.0001)$ (table 1$)$.

In patients with peanut allergy, 145 had ingested the nut, of which $31.7 \%$ had anaphylaxis (table 1). Thirty two patients developed symptoms despite having only skin or oral contact with peanut, and $8(25 \%)$ of them developed anaphylaxis (table 1). In the 27 patients seen with cashew allergy, 22 had ingested the nut and $19(86.4 \%)$ of these developed anaphylaxis (table 1). Five patients with cashew allergy had only skin or oral contact and one of these patients developed anaphylaxis. In the remaining 9 patients who were seen with allergy to another tree nut, $66.7 \%$ developed anaphylaxis (table 1).

Skin symptoms were the commonest non-anaphylactic clinical symptoms. In the anaphylaxis groups, most children had respiratory symptoms. One child in each of the peanut and cashew nut anaphylaxis groups had both respiratory and cardiovascular symptoms, and one child with peanut anaphylaxis had cardiovascular involvement without respiratory symptoms. A number of patients had anaphylaxis without cutaneous involvement (cashew 30\%, peanut $22.2 \%$ ) (table 2).

Table 1 Proportion of patients with anaphylaxis or non-anaphylaxis who had ingested or had only contact with the relevant nut

\begin{tabular}{|c|c|c|c|c|c|c|}
\hline & \multicolumn{2}{|l|}{ Peanut } & \multicolumn{2}{|l|}{ Cashew nut } & \multicolumn{2}{|l|}{ Other nuts } \\
\hline & $\begin{array}{l}\text { Anaphylaxis } \\
\text { (\%) }\end{array}$ & $\begin{array}{l}\text { Non-anaphylaxis } \\
\text { (\%) }\end{array}$ & $\begin{array}{l}\text { Anaphylaxis } \\
\text { (\%) }\end{array}$ & $\begin{array}{l}\text { Non-anaphylaxis } \\
(\%)\end{array}$ & $\begin{array}{l}\text { Anaphylaxis } \\
\text { (\%) }\end{array}$ & $\begin{array}{l}\text { Non-anaphylaxis } \\
(\%)\end{array}$ \\
\hline $\begin{array}{l}\text { Total } \\
\text { Contact only } \\
\text { Ingestion }\end{array}$ & $\begin{array}{l}54 / 177(30.5)^{*} \\
8 / 32(25) \\
46 / 145(31.7)\end{array}$ & $\begin{array}{l}123 / 177(69.5) \\
24 / 32(75) \\
99 / 145(68.3)\end{array}$ & $\begin{array}{l}20 / 27(74.1)^{*} \\
1 / 5(20) \\
19 / 22(86.4)\end{array}$ & $\begin{array}{l}7 / 27(25.9) \\
4 / 5(80) \\
3 / 22(13.6)\end{array}$ & $\begin{array}{l}6 / 9(66.7) \\
1 / 1(100) \dagger \\
5 / 8(62.5) \ddagger\end{array}$ & $\begin{array}{l}3 / 9(33.3) \\
0 \\
3 / 8(38.5) \S\end{array}$ \\
\hline
\end{tabular}

${ }^{*} p<0.0001$

†1 mixed beer nuts.

$\$ 1$ almond, 1 pecan, 1 Brazil, 1 mixture of Brazil and cashew, and 1 fruit \& nut chocolate bar.

§1 almond, 1 walnut, and 1 hazelnut. 


\begin{tabular}{|llll|}
\hline Table 2 Clinical symptoms & & \\
\hline & Symptoms & $\begin{array}{l}\text { Peanut } \\
\mathbf{n}=54(\%)\end{array}$ & $\begin{array}{l}\text { Cashew nut } \\
\mathbf{n}=20(\%)\end{array}$ \\
\hline Anaphylaxis & Respiratory & $11(20 \cdot 4)$ & $3(15)$ \\
& Respiratory/CVS/skin & $1(1.9)$ & $1(5)$ \\
& Respiratory/skin/GIT & $17(31.5)$ & $5(25)$ \\
& Respiratory and skin & $23(42 \cdot 6)$ & $8(40)$ \\
& Respiratory and GIT & $1(1.9)$ & $3(15)$ \\
& CVS/skin/GIT & $1(1.9)$ & 0 \\
\hline & Symptoms & Peanut & Cashew nut \\
& Skin/GIT & $\mathbf{n}=123(\%)$ & $\mathbf{n}=7(\%)$ \\
\hline Non-anaphylaxis & $8(6.5)$ & 0 \\
& Skin & $111(90 \cdot 2)$ & $7(100)$ \\
\hline GIT & $4(3.3)$ & 0 \\
\hline
\end{tabular}

\section{DISCUSSION}

In our cohort, more patients presented with peanut than cashew allergy, which is in keeping with previous studies. ${ }^{1-3}$ However, anaphylaxis was more common in the cashew group. This appears to confirm our clinical suspicion and the findings of others ${ }^{4}$ that cashew appears to be at least as significant an allergen as peanut, and cashew allergy is associated with a high risk of anaphylaxis.

Most of the children had ingested the relevant nut and a significant number developed anaphylactic symptoms. A number of patients had anaphylaxis following only skin or oral mucosal contact with the relevant nut, which may be due to the nut allergen being transferred from hand to mouth, and suggests a significant reaction to minute quantities of allergen. In both groups, cutaneous symptoms were the commonest non-anaphylactic symptoms experienced, which is in keeping with findings observed by previous authors. ${ }^{2-4}$ A number of patients had anaphylaxis without cutaneous involvement, a finding that has been confirmed by others. ${ }^{2-4}$ This has important clinical implications as some medical practitioners may fail to recognise anaphylaxis in the absence of skin symptoms.

In conclusion, we have shown that in our study population cashew nut allergy was more frequently associated with anaphylaxis than peanut allergy. Cashew nut allergy needs to be afforded the same recognition as peanut allergy, and widespread education of medical practitioners and the general public regarding its severity is imperative. Anaphylaxis to peanut and tree nuts can occur without cutaneous involvement. Respiratory symptoms are the commonest anaphylactic symptom in children. Further studies are needed to clarify whether cashew allergy remains a life long problem.

\section{ACKNOWLEDGEMENTS}

We thank Dr Robert Ware (School of Population Health, University of Queensland, Brisbane, Australia) for assistance with the statistics.

\section{Authors' affiliations \\ M Davoren, J Peake, Department of Paediatrics and Child Health, University of Queensland, Royal Children's Hospital, Herston Road, Herston, Brisbane, Queensland 4029, Australia \\ Competing interests: none}

Correspondence to: Dr J Peake, Department of Paediatrics and Child Health, University of Queensland, Royal Children's Hospital, Herston Road, Herston, Brisbane, Queensland 4029, Australia; i.peake@uq. edu.au

\section{Accepted 21 May 2005}

\section{REFERENCES}

1 Armstrong D, Rylance G. Definitive diagnosis of nut allergy. Arch Dis Child 1999;80:175-7.

2 Sicherer SH, Burks AW, Sampson HA. Clinical features of acute allergic reactions to peanut and tree nuts in children. Pediatrics 1998;102:e6.

3 Ewan PW. Clinical study of peanut and nut allergy in 62 consecutive patients: new features and associations. BMJ 1996;312:1074-8.

4 Rancè $F$, Bidat E, Bourrier T, et al. Cashew allergy: observations of 42 children without associated peanut allergy. Allergy 2003;58:1311-16.

5 Hourihane JO'B, Harris H, Langton-Hewer S, et al. Clinical features of cashew allergy. Allergy 2001;56:252-3.

6 Anaphylaxis Working Party of the Australasian Society of Clinical Immunology, Allergy (ASCIA). Guidelines for Epipen prescribing www.allergy.org.au/anaphylaxis/index.htm. 